\title{
O APAGAMENTO DA DINÂMICA DE FORMAÇÃO DO DIREITO NOS MARCOS DA TEORIA TRADICIONAL: UM OLHAR CRÍTICO
}

\author{
Thiago Ferrare Pinto ${ }^{1}$
}

\begin{abstract}
Resumo
A teoria moderna do direito surge com o objetivo de racionalizar a operação cotidiana do fenômeno jurídico. De modo geral, o desafio positivista em torno da potencial contingência do conteúdo do direito põe à teoria tradicional a obrigação de formular parâmetros universais que sustentem a cientificidade do conhecimento jurídico: uma teoria das fontes do direito e uma teoria da interpretação jurídica são temas caros à ciência jurídica moderna. Pretende-se aqui explicitar a concepção de direito pressuposta por aquilo que chamaremos de teoria tradicional do direito. Por teoria tradicional nos referimos ao modo de racionalização do fenômeno jurídico que o isola de dinâmicas sociais a partir de exigências de sistematicidade, unidade e coerência. Também a linhagem dominante da teoria contemporânea se vale da compreensão tradicional do direito, o que implica certa percepção da relação que se estabelece entre o Estado e a sociedade civil na produção de normatividade social. Sustentaremos que, sob o signo da teoria tradicional, o direito é esvaziado enquanto espaço de luta por liberdade.
\end{abstract}

Palavras-chave: teoria do direito; pós-positivismo; teoria crítica; ponderação.

\section{O DIREITO COMO ALTERNATIVA A GUERRA DE TODOS CONTRA TODOS}

Cortar as cabeças da Hidra: segundo Platão (1983, p. 174), seria essa a única e exígua função das leis do Estado. Com isso se quer dizer que tentar unir o corpo político em vias de desconstituição é missão tardia, algo que somente pode cooperar para o adiamento daquilo que é inexorável, a saber, o dilaceramento dos vínculos éticos. Tendo ganhado novos contornos no medievo, tal compreensão da função do direito positivo - concepção que marca, de modo geral, o comunitarismo grego - não resiste aos processos de modernização política. A filosofia política moderna se constrói a partir da pressuposição do desacoplamento do sujeito em relação ao seu contexto social, algo que corresponde, em termos prático-políticos, à sujeição do corpo ao intelecto.

Estendido sobre a mesa, o corpo se objetifica; objetificado o corpo, esvai-se qualquer vestígio de alma enquanto fonte de vida:

That contrary

Both Elements, and Passions liv'd at peace

In her, who caus'd all Civill warre to cease.

\footnotetext{
${ }^{1}$ Doutorando em Direito pela PUC-RJ. Professor substituto do Departamento de Teoria do Direito da Faculdade Nacional de Direito FND/UFRJ. E-mail: thiagoferrarepinto@gmail.com
} 
She, after whom, what for me soe're we see,

Is discord, and rude incongruitte,

Shee, shee is dead, she's dead ${ }^{2}$ (DONNE, 1991, p. 60).

A morte da alma do mundo dá a indicação do novo sentido da ação política. Não mais se vinculando ao fazer valer as normas éticas da comunidade, ela assume a função básica de prover a manutenção e expansão do poder em face da rede ilimitada de interações estratégicas entre os indivíduos isolados (HONNETH, 1992, p. 197-217). Se é a inclinação à autopreservação que dá sentido à conduta subjetiva, há que se dispor de um meio eficaz à ordenação daquilo que é essencialmente caótico; tal meio é a força.

Pela força se alcança o ser humano em sua essência, em sua natureza forjada ao redor de "um sentimento que não se abandona nunca” (MAQUIAVEL, 1983, p. 70): o receio do castigo ou, na formulação de Hobbes (1999, p. 109), “o medo da morte violenta”. Interessa-nos pensar o expediente técnico de que lança mão o poder político com o objetivo de conferir sentido àquilo que, sem a sua intervenção vertical e determinante, permanece desordenado. Trata-se do direito, que aqui se toma em sua roupagem distintamente moderna. Assim compreendida, a força juridicamente fundada se torna um método astucioso de manejar o instrumental político; em outras palavras, os padrões oficiais de conduta são concebidos a partir de sua cisão em relação ao mundo da vida compartilhado. À verticalidade da coação jurídica corresponde, portanto, o distanciamento abrupto do binômio facticidade-validade: o direito moderno se absolutiza enquanto exigência puramente contrafactual.

Tentaremos entender esta concepção do direito em correlação com o ideal moderno de liberdade. O direito moderno ganha sentido à luz de exigências de ordenação de um espaço preenchido por indivíduos atomizados: é da necessidade de fazer coexistir diferentes átomos autoinclinados que surge o direito enquanto ferramenta de gestão social de conflitos. Tal discussão nos servirá de fio condutor nos caminhos da elucidação da relação que se estabelece entre Estado e sociedade civil no seio da teoria tradicional do direito.

De modo básico e enciclopédico, cumpre refazer o caminho pelo qual, de Maquiavel a Locke, ganham força os pressupostos da compreensão moderna e liberal de liberdade política. Tratando da questão sobre se é melhor ser temido ou amado, Maquiavel (1983, p. 70) assim compreende a fonte do ódio do povo em relação ao príncipe:

Deve, portanto, o príncipe fazer-se temer de maneira que, se não se fizer amado, pelo menos evite o ódio, pois é fácil ser ao mesmo tempo temido e não odiado, o que sucederá uma vez que se abstenha de se apoderar dos bens e das mulheres dos seus cidadãos e dos seus súditos, e, mesmo sendo obrigado a derramar o sangue de alguém, poderá fazê-lo quando houver justificativa conveniente e causa manifesta.

Interessa aqui compreender o sentido da ideia de justificativa conveniente para o exercício do poder político. Fundamentalmente, assim se apresenta a questão: toda manifestação do poder político deve justificar-se à

\footnotetext{
2 “[...] mesmo contrárias/ Espécies, ou paixões, se conciliavam nela,/ Que punha fim a toda e qualquer luta interna./ E, depois dela, toda forma que existe/ É só discórdia, incongruência, anomalia./ Ela, ela morreu, é morta. E pensar nisto/ É constatar que o mundo é um monstro malquisto:/ Dest'arte tu aprendes com nossa anatomia/ Que não há nada aqui que possa enamorar-te”.
} 
luz das exigências de manutenção e incremento de poder, de onde resulta que qualquer concessão que se faça aos súditos - à liberdade dos súditos - deve permitir-se interpretar como estratégia para a perpetuação de tal poder. $\mathrm{O}$ que daí se segue é que não há margem alguma para o exercício da vontade livre, uma vez que as eventuais prerrogativas individuais somente são exigíveis quando podem ser somadas ao cálculo direcionado à estabilidade do príncipe.

Nessa medida - e embora tenha antecipado o padrão de atuação política que veio a se hegemonizar no solo moderno -, Maquiavel ainda não alcança a plenitude dos pressupostos da liberdade civil. De fato, é Hobbes quem, avançando a hipótese contratualista, evidencia a essência da filosofia liberal: haja vista que todos os atos individuais estão voltados ao benefício de quem os pratica - é dizer, à autopreservação -, é pelo pacto de cada um com cada um dos indivíduos que se forma o poder político legítimo. A superação do estado de natureza, portanto, é a passagem do caos à ordem legítima, ou seja, à ordem cujos mandamentos encontram-se autorizados perante os participantes da comunidade política. Ocorre, porém, que o Leviatã ainda tem algo do príncipe maquiaveliano: no dizer de Hobbes (1999, p. 144), a pessoa constituída no poder pela multidão está autorizada a usar a força e os recursos de todos "da maneira que considerar conveniente", ainda que essa conveniência seja sempre voltada estrategicamente à paz è defesa comum.

Locke vê na solução hobbesiana uma espécie de contradição interna. Se a saída do estado de natureza resulta da limitação do direito dos membros da comunidade, como conceber um estado civil em que o poder do governante seja ainda ilimitado? Tal significaria, ao contrário, a perpetuação do estado originário em um novo nível, agora com o desequilíbrio - em favor do Leviatã - quanto à possibilidade de uso da força. Seria essa a razão, ainda na linha argumentativa de Locke, pela qual a afirmação de Hobbes (1999, p.175) no sentido de que "todo súdito tem liberdade em todas aquelas coisas cujo direito não pode ser transferido por um pacto" permaneceria desprovida de qualquer consequência relevante, já que no trato cotidiano da ação política o soberano agiria em conformidade com as diretrizes voltadas à garantia da ordem social.

A partir desses pressupostos, portanto, Locke dá conteúdo ao contrato constitutivo do estado civil, conteúdo que deriva do direito natural que rege o estado de natureza:

O "estado de natureza" é regido por um direito natural que se impõe a todos, e com respeito à razão, que é este direito, toda a humanidade aprende que, sendo todos iguais e independentes, ninguém deve lesar o outro em sua vida, sua saúde, sua liberdade ou seus bens (LOCKE, 2006, p. 84).

Se é assim, a atividade do poder político somente é justa à medida que se baseia em tais preceitos do direito natural, de onde se retira a completude dos pressupostos do modelo liberal de vontade livre. Ligada intrinsecamente à autopreservação, a ação individual "deve estar livre de qualquer poder superior na terra, [...] desconhecendo outra regra além da lei da natureza" (LOCKE, 2006, p. 95). Com isso se quer dizer que o ser humano, "incapaz de dispor de sua própria vida, não poderia, por convenção ou por seu próprio consentimento, 
[...] reconhecer em quem quer que seja um poder arbitrário absoluto para dispor de sua vida quando lhe aprouver" (LOCKE, 2006, p. 95). Resta formulada, portanto, a concepção liberal de liberdade: diante de uma medida oficial que viole as prerrogativas que lhe são outorgadas pelo direito natural, o indivíduo pode e deve - já que esse é um imperativo proveniente de seu impulso à autoconservação - desobedecer; em outras palavras, deve ele estar sempre disposto a proteger sua liberdade em face das tendências expansivas da comunidade política organizada.

Sob o signo de tal compreensão de liberdade desenvolveu-se a teoria moderna do direito. A passagem da compreensão moderna da liberdade ao modelo hegemônico de trato com o fenômeno jurídico ocorre aproximadamente da seguinte forma. Sem o poder soberano - e dada a tendência expansiva da liberdade individual -, a vida social permanece desintegrada. O Estado, portanto, ordena e gerencia as tendências desagregadoras inerentes à vivência compartilhada. Uma vez que tenha por função conferir ordem àquilo que tende à desordem, o Estado não pode produzir normatividade de forma contingente e assistemática. É dizer: o instrumento de que se vale o poder soberano para garantir ordem social deve ser coerente, unitário e sistemático. Do contrário - eis a pressuposição da teoria tradicional -, a própria razão de ser do Estado ruiria, dado que a unidade da fonte de produção de normas jurídicas não se converteria na garantia de sistematicidade das normas que são produto de sua atividade.

Diante desse quadro, a teoria do direito assume a função de investigar o traço definidor do fenômeno jurídico. À luz do argumento desenvolvido no parágrafo anterior, é possível perceber que tal traço se relacionará tanto com a proveniência estatal das normas jurídicas quanto com a necessidade de que a produção normativa do Estado obedeça a parâmetros de unificação do discurso:

Que o direito seja aquele conjunto de regras que se fazem valer ainda que pela força [...] é a conclusão a que julgamos ter chegado no livro precedente. [...] o que essa teoria da soberania convida a observar, antes de tudo, é que, definido o direito através do poder soberano, já se realizou o salto da norma isolada para o ordenamento em seu conjunto. [...] uma definição satisfatória do direito só é possível se nos colocarmos do ponto de vista do ordenamento jurídico (BOBBIO, 1995, p. 25 e 22).

Do ponto de vista do ordenamento jurídico, o direito é definido em termos de unidade, coerência e completude. Conferir racionalidade ao fenômeno jurídico consiste então no esforço de expurgar inconsistências por meio de critérios universais de lida com fissuras no encadeamento da normatividade jurídica: para fazer sentido da unidade da ordem jurídica, elabora-se uma teoria das fontes do direito; para suprimir antinomias e garantir coerência, forjam-se critérios hierarquizados para a aferição da validade jurídica de normas; em face de lacunas na ordem jurídica, a completude do direito é reposta e justificada por meio de critérios de integração sistêmica. Se o direito é obra do poder soberano; e se a razão de ser do poder soberano é a garantia da ordenação social, a teoria do direito ganha importância por pensar em estruturas de integração do discurso sobre normas sociais.

Estreitando as distâncias entre a teoria do direito e a prática do fenômeno jurídico que ela pretende 
racionalizar, é possível abordar o direito como um espaço de unificação formal da justificação de padrões de ação. Realidade e juridicidade se tocam somente em ocasiões nas quais a dinâmica da vida social impõe a revisão dos marcos formais do fenômeno jurídico: mesmo quando desafiado em sua unidade, coerência e completude, o direito repõe-se enquanto estrutura formal por meio dos critérios unificadores desenvolvidos pela teoria tradicional. Nada de produtivo se encontra na vivência cotidiana de indivíduos autointeressados, na vivência cotidiana da sociedade civil desmobilizada. A sistematicidade do direito é a alternativa cunhada pela modernidade para livrar-se da angústia improdutiva da luta de todos contra todos.

Assim alcançamos um dos traços centrais daquilo que chamamos de teoria tradicional do direito: a compreensão do direito enquanto instrumento de que dispõe o titular do poder político para fins de estabilizar a vida social e garantir o seu regular funcionamento. O fenômeno jurídico se justifica por oposição à ameaça de desordem, de onde se segue sua externalidade em relação à dinâmica social cotidiana.

\section{UMA VIDA POLÍTICA PROCEDIMENTALIZADA: ESTADO E SOCIEDADE CIVIL}

Tomemos o direito como meio abstrato de ordenação da vida compartilhada. Aceitemos também os pressupostos de tal concepção: se o direito é a alternativa à desordem, a vida sem direito é caótica. A passagem, portanto, da desorganização à organização se dá pela acoplagem do poder político unitário aos desenvolvimentos da sociedade civil. A questão aqui é a seguinte: mesmo após justificar a emergência do poder político pela necessidade de garantir ordem, a teoria tradicional do direito ainda mantém a distinção entre a sociedade civil desorganizada e o Estado como instância de unificação de discursos, como instância de ordenação. Nestes termos, a vivacidade da vida política de uma comunidade se restringe às vias de passagem das vontades dispersas de cada um dos titulares de direitos políticos para a plataforma unificadora do poder oficial. Política se resume, portanto, à unificação de vontades pela via procedimental. Investigaremos essa dimensão da racionalização da compreensão hegemônica do direito a partir do liberalismo político de John Rawls.

Segundo Rawls (2000, p. 32-33), "o sucesso do constitucionalismo liberal manifestou-se como a descoberta de uma nova possibilidade social: a possibilidade de uma sociedade pluralista estável e razoavelmente harmônica". A ideia da sociedade como sistema equitativo de cooperação funcionará como ponto de partida para se pensar o emaranhado de compromissos que se encontram implícitos no engajamento intersubjetivo em torno das estruturas de um estado constitucional: o equilíbrio reflexivo deverá fundar a legitimidade da justiça como equidade como produto verossímil do exercício público do autoesclarecimento.

Tomar a existência da vida social como sistema equitativo de cooperação resulta na assunção de ao menos dois pressupostos: por um lado, Rawls vincula seu projeto a uma concepção específica de pessoa; por outro, exige a elaboração da ideia de sociedade bem-ordenada. Tomaremos cada um dessas noções como fio 
condutor de nossa exposição.

Opondo-se à alegação de que a justiça como equidade pressuporia uma concepção metafísica do el, Rawls elabora aquilo que chama de concepção política de pessoa. De modo geral, o objetivo do autor consiste em se livrar da ideia de que o expediente de fundamentação do equilíbrio reflexivo dos dois princípios de justiça envolveria a padronização de certo modelo abstrato de subjetividade: o sujeito capaz de razão seria aquela entidade não contaminada pela contingência do mundo social, uma máquina capaz de acessar desde uma posição alheia à intersubjetividade uma perspectiva neutra e objetivamente válida. Rawls não pretende fazer coro a tal perspectiva, de modo que relaciona à sua concepção de pessoa três aspectos a partir dos quais, "na cultura política pública de um regime democrático constitucional, os cidadãos concebem a si mesmos como livres":

Primeiro, os cidadãos são livres no sentido de conceberem a si mesmos e aos outros como indivíduos que tem a faculdade moral de ter uma concepção de bem. [...] Um segundo aspecto em relação ao qual os cidadãos se veem como livres é que se consideram fontes autoautenticadoras de reivindicações válidas. [...] $\mathrm{O}$ terceiro aspecto pelo qual os cidadãos são vistos como livres diz respeito a serem percebidos como capazes de assumir responsabilidades por seus objetivos, [...] de modo que seja possível realizá-los de acordo com os meios que podem razoavelmente esperar obter em troca daquilo com que podem razoavelmente esperar contribuir (RAWLS, 2000, p. 73, 76, 77-8).

Fundamental é não tomar tal concepção de pessoa como um meio de essencialização da natureza humana. Em verdade, Rawls evidencia a centralidade da perspectiva kantiana no desenvolvimento de toda e qualquer abordagem filosófica que se pretenda crítica: "Kant é o primeiro pensador a assumir explicitamente como tarefa a explanação de nossas características enquanto seres discursivos, em termos de nossa responsabilidade em relação aos vários tipos de compromissos normativos" (BRANDOM, 2002, p. 22, tradução livre $)^{3}$. É pela via da virada normativa que se pode compreender a unidade dos três traços da pessoa. Sendo assim, a tese a ser retida nesse ponto consiste na defesa da capacidade humana para o exercício da autorreflexão, para o exercício da consciência de si enquanto experiência comunicável.

Ainda no âmbito da concepção política de pessoa - portanto, no âmbito do primeiro dos pressupostos envolvidos na assunção do ponto de partida segundo o qual a sociedade é um sistema equitativo de cooperação -, Rawls esclarece uma série de mal-entendidos que pairam sobre aquilo que desde a Teoria chamou de posição original. Para uma parte dos leitores de sua obra, a posição original soaria como pura idealidade: para além de pressupor um "eu ontologicamente anterior aos fatos sobre a pessoa" (RAWLS, 2000, p. 70), o véu da ignorância faria evidente o fato de que a concepção política de justiça que Rawls pretende fundamentar não possui qualquer respaldo nos enlaces constitutivos da vida cotidiana. Tal leitura não se sustenta.

Segundo Rawls (2000, p. 66), "a justiça como equidade retoma a doutrina do contrato social". Tal retomada, porém, deve ser concebida como atualização: de modo acurado, podemos dizer que Rawls pretende 
reposicionar a teoria do contrato social num ambiente pós-metafísico de discussão. O sentido básico da atualização pode ser compreendido se tomarmos a posição original não como o momento de transição do estado de natureza - conflituoso, como em Hobbes; ou potencialmente conflituoso, como em Locke - para o estado civil ordenado pela autoridade única. Longe disso, a posição original surge aqui "como um meio de reflexão e auto-esclarecimento públicos": "podemos, por assim dizer, entrar nessa posição a qualquer momento simplesmente argumentando em favor de princípios de justiça em consonância com as restrições à informação" (RAWLS, 2000, p. 69-70).

O conjunto das restrições que fundam a posição original nos permite concluir que Rawls quer designar aqui o espaço de justificação de juízos com pretensão de imparcialidade e objetividade. Fundamental é asseverar que não há uma descontinuidade entre a cooperação equitativa na vida social cotidiana e o momento de justificação que nos alça à posição original: o véu da ignorância quer fazer evidente o fato de que a posição original - à medida que se presta à justificação dos padrões últimos de coordenação da vida compartilhada - nada mais é do que a instância no qual o sujeito se descentra e leva a sério as restrições argumentativas que funcionam como condição do acesso imparcial àquilo que em certa sociedade pode ser tomado como a melhor concepção política de justiça.

Assim exposta a concepção política de pessoa, passemos ao segundo desdobramento da tese segundo a qual a sociedade é um sistema equitativo de cooperação. Trata-se aqui da ideia de sociedade bem-ordenada. Assim Rawls elabora esta noção:

Dizer que uma sociedade é bem-ordenada significa três coisas: a primeira (e isso está implícito na ideia de uma concepção de justiça publicamente reconhecida), que se trata de uma sociedade na qual cada indivíduo aceita, e sabe que todos os demais aceitam, precisamente os mesmos princípios de justiça; a segunda (implícita na ideia de regulação efetiva), que todos reconhecem, ou há bons motivos para assim acreditar, que sua estrutura básica - isto é, suas principais instituições políticas, sociais e a maneira segundo a qual se encaixam num sistema único de cooperação - está em consonância com aqueles princípios; e a terceira, que seus cidadãos tem um senso normalmente efetivo de justiça e, por conseguinte, em geral agem de acordo com as instituições básicas da sociedade, que consideram justas (RAWLS, 2000, p. 79).

Rawls supõe que uma sociedade bem-ordenada se estrutura em torno do compartilhamento por seus membros de certa concepção de justiça. De modo geral, a isso o autor dá o nome de consenso sobreposto. Pensar a existência compartilhada de certa compreensão de princípios políticos de justiça envolve a pressuposição de que as visões de mundo dos cidadãos possam ser tomadas sob uma dupla perspectiva: "pode-se considerar uma parte como a concepção política de justiça publicamente reconhecida, ou como coincidente com ela; a outra parte é uma doutrina (inteira ou parcialmente) abrangente, à qual a concepção política está ligada de alguma forma”

\footnotetext{
3 "Kant is the first thinker explicitly to take as his task the explanation of our character as discursive creatures in terms of our liability to various kinds of normative assessment" (BRANDOM, 2002, p. 22).
} 
(RAWLS, 2000, p. 82).

É preciso manter presente que a produção social do consenso sobreposto somente se faz possível no ambiente de uma democracia constitucional estável. Isso porque tal consenso se ergue do bojo daquilo que Rawls chama de fato do pluralismo razoável: "Instituições livres tendem a gerar não apenas uma grande variedade de doutrinas e visões de mundo. [...] o que ocorre, pelo contrário, é que, entre as visões que se desenvolvem, existe uma diversidade de doutrinas abrangentes e razoáveis. São as doutrinas que os cidadãos razoáveis professam e com as quais o liberalismo político tem de lidar" (RAWLS, 2000, p. 80). Dito de outra forma, uma concepção abrangente razoável é aquela que se deixa harmonizar com as premissas que estruturam uma democracia constitucional; é aquela, portanto, que pode conviver no espaço público por não colocar em risco o coração normativo que funda a unidade da vida social.

As ideias de cooperação equitativa, posição original e consenso sobreposto apontam para o último dos traços da obra de Rawls que aqui nos interessa investigar. Refiro-me à ideia de construtivismo político. Em primeiro lugar, a oposição se faz em relação ao realismo moral. A suposição de um sustentáculo extramundano para a validade dos juízos morais - a lei de Deus ou a natureza das coisas, por exemplo - faria de nós meros expectadores do fundamento de validade da ordem que nos regula; fundamento que seria acessível por intuição, portanto. Em segundo lugar, tal ideia se diferencia do construtivismo moral: Kant teria recaído numa doutrina abrangente, o que quer dizer que sua formulação dos fundamentos da moralidade proveria a unidade das pretensões de validade ao custo das tendências pluralistas inerentes à vida moderna.

A posição de Rawls nos permite ver que uma concepção política de justiça que se pretenda legítima precisa estar apoiada no compromisso transversal em torno das estruturas fundamentais da cooperação equitativa; precisa estar apoiada, portanto, no consenso sobreposto. Daí então que se possa dizer que tal concepção é construída por pessoas livres e iguais na efetivação cotidiana dos padrões que fundam a estabilidade da comunidade política. A posição original e o véu da ignorância respaldam a perspectiva segundo a qual o discurso livre no espaço de justificação teria por resultado a compreensão dos princípios da justiça como equidade como aqueles responsáveis pela estabilidade da cooperação: o consenso sobreposto e a justiça como equidade enquanto concepção política de justiça sustentada no equilíbrio reflexivo dão o tom do construtivismo político de Rawls.

Perceber em que se sentido a concepção política de Rawls pode ser tomada como incorporação de traços fundamentais da teoria tradicional do direito envolve a correta análise do modo pelo qual se dá a lida do constitucionalismo liberal com o pluralismo de concepções de bem. O consenso constitucional que apoia a ordenação e a estabilidade da sociedade civil tem por conteúdo critérios mínimos para o reconhecimento da razoabilidade das diferentes concepções de bem: o particularismo das diversas compreensões de mundo somente 
se faz legítimo se puder conviver com parâmetros compartilhados em torno do que seja a razão pública. Reiterando este ponto, tem-se que o caráter razoável de todo e qualquer modo de vida particular se mede pela possibilidade de sua convivência harmônica num espaço estruturado por critérios publicamente reconhecidos de formação da vontade política.

O ponto é: o liberalismo político lida com o pluralismo, mas não faz dele algo produtivo. E não o faz por supor uma espécie de externalidade entre os diversos particularismos; externalidade que seria somente operacionalizada - e nunca superada - pelos procedimentos instituídos em um Estado democrático de direito. A estrutura constitucional da comunidade política se prestaria à mediação entre uma sociedade civil dispersa em suas concepções de bem individualistas e o espaço público de deliberação sobre os destinos da vida compartilhada. O liberalismo concebe o Estado e a sociedade civil como sistemas autônomos, ambos ordenados em torno de imperativos de ação estratégica. Pensar o processo de formação da vontade política seria, portanto, investigar os meios através dos quais se relacionam essas duas instâncias externas: se as instâncias são externas e funcionam através de modos autônomos de reprodução, a mediação entre elas há de ser formal e abstrata. Assim é que ganham forma os processos de formação da vontade política enquanto estratégias de agregação de interesses privados (HABERMAS, 2002, p. 278). Tal modo de conceber o processo político nos conduz à concepção liberal daquilo que seja um agente político, um cidadão politicamente ativo: cidadão é aquele que possui a garantia de proteção e de validação intersubjetiva de seus interesses privados. Política, portanto, é cálculo; é o fazer valer das inclinações particulares por meio de princípios constitucionais que supostamente lhes conferem validade universal.

Há aqui carência de teoria social. A externalidade entre a vontade de cada um dos indivíduos e a orientação do poder oficial não pode ser superada sem a percepção de que a narrativa comunitária é condição da construção de subjetividades. A ideia de mediação intersubjetiva da subjetividade nos obriga a pensar a política não enquanto local de ações voltadas ao interesse individual, mas como espaço de busca pelas condições de individualização e formação prática. Sob essa perspectiva, é possível perceber que o constitucionalismo que simplesmente lida com a diversidade perde de vista a própria razão de ser de uma Constituição: o compromisso constitucional não é fruto da razão estratégica - ele não nasce à maneira do Leviatã hobbesiano; longe disso, ele é resultado da consciência de que os agentes de certa comunidade política encontram-se enredados num só destino. A determinação da vontade individual pela comunidade é algo inescapável. Resta ao sujeito, portanto como exigência do ideal moderno de autodeterminação -, engajar-se nos processos de decisão sobre os caminhos da vida compartilhada.

Retomando nosso ponto. A pressuposição da cisão entre Estado e sociedade civil - bem como a operacionalização desta cisão pela via procedimental - é um traço fundamental da teoria tradicional do direito. A 
produção social do conteúdo normativo que ordena a vida social se faz possível pela instituição de vias por meios das quais se supera o abismo existente entre a dispersão particularista da sociedade e a necessidade de unificação do discurso do poder oficial.

\section{SUBSUNÇÃO, PONDERAÇÃO E RACIONALIZAÇÃO ABSTRATA: A COMPLEXIFICAÇÃO DO EXPEDIENTE ORDENADOR}

Ainda no âmbito dos padrões hegemônicos de lida com o fenômeno jurídico, é preciso que se diga algo sobre a racionalização da atividade jurisdicional. Pretende-se defender a ideia de que a teoria da interpretação e aplicação do direito - seja em sua versão tradicional, seja em seus desdobramentos contemporâneos - se sustenta na pressuposição da cisão entre Estado e sociedade civil. Seria possível, portanto, falar de tais disciplinas como espaços de justificação da abstrata localização do Estado enquanto produtor exclusivo de normatividade social.

Tornou-se senso comum a narrativa a respeito de uma recente mudança no modo hegemônico de se compreender o direito:

[...] processo em curso na experiência jurídica liga-se à ampliação do espaço no qual o interpretação jurídica e o intérprete estão autorizados a transitar. É fácil perceber que existe um vínculo entre essa ampliação e a reaproximação com os valores e a moral: tendo em conta sua abertura e abstração características, a aplicação de valores a casos concretos, ainda que veiculados sob a forma de princípios, exigirá do intérprete um esforço considerável de integração (BARCELLOS, 2005, p. 9).

A ciência jurídica que tomou forma na Europa do século XIX sustentou-se na pretensão de verdade própria às ciências de seu tempo: pretendia objetividade e imparcialidade para suas proposições, o que significava restringir as preocupações da teoria do direito à descrição das normas emanadas do Estado. A unidade na produção do direito era racionalizada pela ciência jurídica através da formulação de critérios uniformes de interpretação e aplicação da lei. Em termos de aplicação, a ideia de subsunção centraliza o pressuposto da completude e autossuficiência do direito formal, uma vez que nesse modelo de aplicação do direito o mundo empírico se faz relevante somente enquanto exemplo da previsão abstrata da norma jurídica.

A subsunção é o modelo que a ciência jurídica do século XIX cunhou para falar da racionalização do argumento jurídico. A neutralidade do operador ${ }^{4}$ do direito se funda na estreiteza da tarefa que lhe cabe. Diante de algum fato juridicamente relevante, o intérprete e aplicador deve debruçar-se sobre as tábuas do direito positivo com o objetivo de confirmar se o fato em análise pode ser tomado como exemplo de certa previsão normativa. Se a resposta for positiva, basta subsumir o fato à norma e retirar daí as consequências previamente estabelecidas para

\footnotetext{
${ }^{4}$ Chama atenção o perfil abstrato impresso no campo semântico da palavra operador. Opera-se uma máquina, um objeto naturalizado e passível de antecipação em seus futuros movimentos. Este termo, portanto, ganha sentido no contexto teórico da compreensão do direito a partir dos critérios de unidade, sistematicidade e coerência. Pressupor a possibilidade de operaro direito é tomá-lo como algo estático e suscetível ao domínio técnico de um especialista.
} 
o enquadramento fático. Nada de novo ocorre no processo de interpretação e aplicação das previsões normativas: ou o fato se enquadra na previsão da norma, de onde se segue a aplicação das consequências juridicamente previstas; ou o fato não é típico, sendo irrelevante para o direito.

A teoria contemporânea do direito parece supor a insuficiência do método subsuntivo. Fala-se aqui do surgimento de um novo marco filosófico para a teorização sobre o direito: o pós-positivismo. As referências sobre tal marco são ambíguas e difusas. Tudo indica, porém, que há certa concordância em torno da seguinte percepção de Barroso (2009, p. 248-9):

A obra seminal de Rawls - Uma teoria da justiça, de 1971 - abre caminho para a ascensão do pós-positivismo, por meio da revalorização da razão prática e da inserção dos princípios de justiça no interior da ordem jurídica. Trata-se da chamada virada kantiana, marco da ascensão do pós-positivismo. [...] O pós-positivismo, ao reabilitar o uso prático da razão na metodologia jurídica, propõe justamente a possibilidade de se definir racionalmente a norma do caso concreto através de artifícios racionais construtivos, que não se limitam à mera atividade de conhecer os textos normativos.

Difícil saber em que sentido se fala aqui de reabilitação do uso prático da razão. Enquanto instância de mediação da ação humana, a razão prática está implicada no trato compromissório da vida compartilhada, de modo que padrões públicos de justificação de ações sempre existirão em interações sociais. É possível analisar o modo como a disseminação de imperativos técnicos - a exemplo dos imperativos que condicionam a neutralidade do juiz positivista - acaba por retirar do espaço público as questões práticas que versam sobre os destinos de certa comunidade política: remonta a Habermas (1980, p. 319) a ideia segundo a qual no capitalismo avançado a técnica substitui "a realização de objetivos práticos por solução de questões técnicas". Falar de reabilitação da razão prática, porém, soa inadequado pela suposição de resgate de algo que a modernidade jamais abandonou - seria possível falar de uma razão prática embotada, falseada ou o que quer que seja, mas nunca de uma razão prática desabilitada.

A perspectiva de Barroso torna-se um tanto mais inadequada quando relaciona tal reabilitação com a ideia de virada kantiana. Por virada kantiana a filosofia ocidental designou uma das teses básicas da filosofia crítica de Kant: a ideia de que a conceitualidade da vida compartilhada compromete-nos irremediavelmente com a justificação intersubjetiva de nossos conceitos; compromete-nos, portanto, com a constante referência ao espaço da unidade sintética da apercepção transcendental ${ }^{5}$. Tomar como nota distintiva do pós-positivismo um movimento que se deu na gênese da filosofia moderna ${ }^{6}$ e não cuidar de distinguir a singularidade do atual

\footnotetext{
${ }^{5}$ Sobre o ponto, ver Brandom, (2002, p. 23-4) e Rorty (1979, p. 131-64).

${ }^{6}$ Sobre a relação entre Kant e o discurso filosófico da modernidade, ver Habermas (2000, p. 29-30): "Kant expressa o mundo moderno em um edifício de pensamentos. De fato, isto significa apenas que na filosofia kantiana os traços essenciais da época se refletem como em um espelho, sem que Kant tivesse conceituado a modernidade enquanto tal. Só mediante uma visão retrospectiva Hegel pode entender a filosofia de Kant como autointerpretação decisiva da modernidade. Hegel visa conhecer também o que restou de impensado nessa expressão mais refletida da época: Kant não considera como cisões as diferenciações no interior da razão, nem as divisões formais no interior da cultura, nem em geral a dissociação dessas esferas. Por esse motivo, Kant
} 
momento das reflexões sobre o direito e a justiça parece temerário. Nosso objetivo, porém, nos permite seguir sem esse esclarecimento. Abstraindo da fragilidade de sua relação com Kant e com a ideia de razão prática, vale dar sequência às investigações sobre o pós-positivismo.

O recurso que Barroso faz a Rawls parece lançar luz sobre um sentido possível para a relação entre razão prática e pós-positivismo. Razão prática para Rawls é o conjunto de parâmetros e limitações discursivas que condicionam o uso público da razão. O critério para saber da razoabilidade de uma concepção de bem seria, portanto, a possibilidade de tal concepção se autolimitar à luz das estruturas que dão forma ao espaço público de uma sociedade plural e razoável. Por aí se chega a um sentido possível para a abordagem de Barroso: a reabilitação da razão prática diria respeito à incorporação ao direito de marcos argumentativos cujo conteúdo normativo remonta aos processos de conquista democrática desenrolados na Europa da segunda metade do século XX. Os processos de aprendizado, portanto, teriam produzido a sedimentação do conteúdo aberto e democrático da razão pública: o espaço de decisões compartilhadas a respeito dos destinos da comunidade política se recuperou pela incorporação ao espaço público daquilo que surgiu no pós-guerra como resultado de aprendizados em face de catástrofes - a centralidade do princípio da dignidade humana é aqui o melhor exemplo.

Se for este o sentido do pós-positivismo, é de fato singular a sua reelaboração da compreensão do fenômeno jurídico. Em primeiro lugar, ruiriam as pretensões positivistas de identificação do direito por meio de critérios formais. Mesmo o positivismo inclusivo perderia suas bases diante da centralização de processos discursivos e horizontais de produção de normatividade. O direito perderia o status de norma abstrata e formal, passando a incorporar-se na normatividade espontânea que estrutura a vida de uma comunidade política: direito, moral e ética não mais seriam distinguíveis em seus âmbitos de regulação, de onde se seguiria a transversalidade do fenômeno jurídico na possível extensão de suas normas a todos os espaços de interação intersubjetiva. $\mathrm{O}$ direito seria um jogo de linguagem, uma linguagem concreta e cotidiana.

E há mais. Se a suposta reabilitação da razão prática implica o resgate do espaço discursivo de tomada de decisões sobre os caminhos da comunidade política, o que se vê é uma subversão do modo como tradicionalmente se concebeu a relação entre Estado e sociedade civil. A passividade da sociedade seria superada pela reposição do ideal de autodeterminação: a agência da sociedade civil seria garantida pela abertura e pela igualdade dos âmbitos públicos de formação da vontade democrática. Mobilizações sociais em torno de demandas emancipatórias encontrariam na justiça das estruturas da esfera pública a garantia da repercussão de suas vozes.

Seria de se esperar ainda que a ressignificação da relação entre Estado e sociedade civil implicasse a

ignora a necessidade que se manifesta com as separações impostas pelo princípio da subjetividade. Essa necessidade se impõe à filosofia assim que a modernidade se concebe como uma época histórica, assim que toma consciência da ruptura com passados exemplares e da necessidade de haurir de si mesma tudo que é normativo, enquanto problemas históricos". 
revisão das temáticas próprias à teoria do direito. Falou-se da amplitude das tarefas tradicionais de tal campo do conhecimento: o Estado surge para ordenar o que é tendencialmente caótico; o instrumento de que se vale, já que sua função é ordenar, precisa ser unitário, coerente e sistemático; se é assim, teoria do direito tradicional cuida das condições para que o direito se faça valer enquanto espaço de ordens unitárias, coerentes e sistemáticas. O preço que se paga na execução cega desta tarefa teórica é a indiferença ao papel produtivo da sociedade civil: o direito é formal e abstrato, o que significa dizer que há um critério de identificação que o distingue e isola de outras formas de normatividade social.

A suposta reabilitação da razão prática implica a centralidade dos espaços públicos de produção de normatividade jurídica. Direito seria o produto de construções discursivas engendradas no seio da sociedade civil. A teoria do direito, portanto, teria de lidar com a contradição que é própria aos fluxos de comunicação de uma sociedade complexa, teria de lidar com o fato de que unidade, coerência e sistematicidade não podem ser tomados como traços definidores de um fenômeno tão horizontal. No limite, as preocupações do teórico do direito em muito se assemelhariam àquelas que são próprias à teoria social e à história política: não mais pensar em padrões abstratos para a definição do direito, mas saber onde e como se estruturam contextos sociais de resistência à opressão, saber em que sentido a história pode ser acessada como espaço de produção de desigualdades. A teoria do direito, portanto, perderia sua pretensão à autonomia formal.

Causa surpresa saber que nada disso se deu no ambiente pós-positivista. De fato, as supostas novidades do cenário jurídico contemporâneo foram enfrentadas a partir do velho ímpeto sistematizador da teoria tradicional do direito. Um ponto ilustra bem a questão. Sob o domínio de certa compreensão do direito, a teoria tradicional falou da subsunção como modo padrão de sua aplicação: o caráter formal e abstrato do direito permitiria a antecipação dos fatos juridicamente relevantes. $\mathrm{O}$ mundo nada diria às normas oficiais. Dada a reabertura do ambiente contemporâneo para o enlace entre direito, moral e ética, seria preciso elaborar novos modos de lidar com a interpretação e aplicação do direito; seria preciso falar em ponderação:

Essa, portanto, é a primeira distinção entre a ponderação e as técnicas tradicionais de solução de antinomias: estas estão ligadas à subsunção, ao passo que a ponderação é uma alternativa a ela. [...] a ponderação será compreendida e identificada como uma técnica jurídica de solução de conflitos normativos que envolvem valores ou opções políticas em tensão, insuperáveis pelas formas hermenêuticas tradicionais (BARCELLOS, 2005, p. 33 e 38).

O trecho citado revela o ponto que queremos explorar. Nos termos de seu marco filosófico, o póspositivismo encarna a promessa de realização plena do ideal de autodeterminação: éa reabilitação da razão prática que está em jogo, a realização plena do ideal kantiano de autolegislação. Ocorre que em termos de racionalização da argumentação jurídica, o novo modelo da ponderação repõe o velho problema da insensibilidade da teoria do direito para os fluxos comunicativos entre Estado e sociedade civil. Uma investigação a respeito do roteiro daquilo que se tem chamado de ponderação nos esclarecerá este ponto. 
A ponderação deve se dar em três etapas, conforme Barroso (2009, p. 334) e Barcellos (2005, p. 91). Na primeira delas, "cabe ao intérprete detectar no sistema as normas relevantes para a solução do caso, identificando eventuais conflitos entre elas" (BARROSO, 2009, p. 334). "Na segunda fase cabe examinar as circunstâncias concretas do caso e suas repercussões sobre os elementos normativos, daí se dizer que a ponderação depende substancialmente do caso concreto e de suas particularidades" (BARCELLOS, 2005, p. 115-16). A terceira etapa marca a singularidade da ponderação em face da subsunção: "[...] nessa fase dedicada à decisão, os diferentes grupos de normas e a repercussão dos fatos do caso concreto serão examinados de forma conjunta, de modo a apurar os pesos que devem ser atribuídos aos diversos elementos em disputa e, portanto, o grupo de normas que deve preponderar no caso" (BARROSO, 2009, p. 335).

A decisão que deve surgir da terceira etapa da ponderação se justifica a partir do respeito a certos parâmetros públicos e argumentativamente controláveis. Barcellos (2005, p. 125) nos fala de tais parâmetros:

Em primeiro lugar, o intérprete deve estar comprometido com a capacidade de universalização tanto dos fundamentos empregados no processo, como da decisão propriamente dita. Em segundo lugar, e como já referido, os esforços do aplicador nesta fase devem ter por meta a concordância prática dos enunciados normativos em conflito. Por fim, uma terceira questão que não pode ser negligenciada nesta fase, quando ela envolva direitos fundamentais, diz respeito ao núcleo dos direitos e o limite que ele representa à ponderação.

O ponto é: a ponderação é uma técnica que confirma os pressupostos fundamentais da teoria tradicional do direito. Não se questiona aqui a novidade do ambiente sociojurídico contemporâneo. A questão é saber do modo como a teoria contemporânea lida com os desafios que este ambiente nos coloca. Coerência, unidade e sistematicidade se repõem a partir da crença de que o direito formal deve a todo custo preservar sua pretensão de universalidade. A grande narrativa em torno do pós-positivismo redunda - para a teoria do direito - na resignada postura de investigação a respeito de um novo método voltado à superação de novos desafios a partir de velhas crenças. Velhos são os ideais de unificação formal e abstrata do direito formal; e são esses ideais que o póspositivismo quer ainda realizar.

Tal como a subsunção e todo o aparato da teoria tradicional, a ponderação não lida com a historicidade do direito. Não lida com a história de formação da estrutura jurídica da comunidade política. A reposição dos ideais abstratos da teoria do direito impede a visualização da gênese das normas jurídicas a partir das relações entre Estado e sociedade civil. O direito não surge no vácuo; ao contrário, ele surge do seio da história, de modo que uma teoria do direito não pode produzir-se na indiferença em relação ao atrito que se estabelece entre formas de vida juridicamente estruturadas e o sofrimento das pessoas que são subalternizadas pelo fluxo uniformizante da história. Ponderação, portanto, é algo que se justifica ainda nos marcos da teoria tradicional do direito.

Um último passo para atestarmos este ponto. Após tratar dos traços históricos e filosóficos do novo direito constitucional contemporâneo, Barroso (2009, p. 338) encaminha suas investigações em um sentido que prova a nossa tese segundo a qual a narrativa do pós-positivismo redunda na reposição do caráter formal e 
abstrato da teoria do direito:

Naturalmente, nas hipóteses em que a solução produzida não decorre de uma lógica subsuntiva, o ônus argumentativo se potencializa, devendo o intérprete demonstrar, analiticamente, a construção do seu raciocínio. Daí a necessidade de se resgatar a argumentação jurídica.

A promessa em torno da reabilitação da razão prática a partir da virada kantiana para por aí: na exigência de rigor formal na argumentação jurídica. Analiticamente estruturada, a argumentação deve curvar-se à controlabilidade do que é lógico, não à necessidade de justificação pública daquilo que é justiça histórica. A ponderação, portanto, é parte da teoria tradicional do direito, desde que a concebamos como a consciência de sié dizer, como o conjunto de conceitos e categorias voltados à fundamentação - de certa concepção do direito que isola Estado e sociedade civil, que retira o direito da história porque o supõe logicamente sustentado.

\title{
THE DELAY OF THE DYNAMICS OF FORMATION OF LAW IN THE FRAMES OF TRADITIONAL THEORY: A CRITICAL LOOK
}

\begin{abstract}
The modern theory of law arises with the objective of rationalizing the day-to-day operation of the legal phenomenon. In general, the positivist challenge regarding the potential contingency of the content of law puts the traditional theory in the obligation to formulate universal parameters that support the scientificity of the legal knowledge: a theory of the sources of the law and a theory of the legal interpretation are two of the main subjects to the modern legal science. It is intended here to explain the conception of law presupposed by what we will call the traditional theory of law. By traditional theory we refer to the way of rationalizing the legal phenomenon that isolates it from social dynamics through requirements of systematicity, unity and coherence. Also, the dominant lineage of contemporary theory is based on the traditional understanding of law, which implies a certain perception of the relationship established between the State and civil society in the production of social normativity. We will argue that under the sign of traditional theory, law is emptied as a space for the struggle for freedom.
\end{abstract}

Keywords: Theory of Law; Post-Positivism; Critical Theory; Weighing

\section{REFERENCIAS}

BARCELLOS, Ana Paula de. Ponderação, racionalidade e atividade jurisdicional. Rio de Janeiro: Renovar, 2005.

BARROSO, Luis Roberto. Curso de direito constitucional contemporâneo: os conceitos fundamentais e a construção do novo modelo. São Paulo: Saraiva, 2009.

BOBBIO, Borberto. Teoria do ordenamento jurídico. Trad. Maria Celeste Santos. Brasília: Universidade de Brasília. 1995. 
BRANDOM, Robert. Tales of the mighty dead: historical essays in the metaphysics of intentionality. Cambridge: Harvard University Press, 2002.

DONNE, John. The first anniversary: an anatomy of the world. In.: SHAKESPEARE, William; et al. Poesia Metafísica. Trad. Aíla de Oliveira Gomes. São Paulo: Companhia das Letras, 1991, p. 50-61.

HABERMAS, Jürgen. A inclusão do outro: estudos de teoria política. Trad. George Sperber e Paulo Astor Soethe. São Paulo: Loyola, 2002.

O discurso filosófico da modernidade: doze lições. Trad. Luiz Sérgio Repa e Rodnei Nascimento. São Paulo: Martins Fontes, 2000.

Técnica e ciência enquanto ideologia. In.: BENJAMIN, Walter; HORKHERIMER, Max; ADORNO, Theodor W; HABERMAS, Jürgen. Textos escolhidos. Coleção Os Pensadores. São Paulo: Abril Cultural, 1980.

HOBBES, Thomas. Leviatã ou Matéria, Forma e Poder de um Estado Eclesiástico ou Civil. Trad. João Paulo Monteiro e Maria Beatriz Nizza da Silva. São Paulo: Nova Cultural, 1999.

HONNETH, Axel. Moral development and social struggle: Hegel's early social-philosophical doctrines. In.: HONNETH, Axel; et al (orgs.). Cultural-Political Interventions in the Unfinished Project of Enlightenment. Cambridge: The Mit Press, 1992, p. 197-217.

LOCKE, John. Segundo Tratado Sobre o Governo Civil e Outros Escritos: ensaio sobre a origem, os limites e os fins verdadeiros do governo civil. Trad. Magda Lopes e Marisa Lobo da Costa. Petrópolis, RJ: Vozes, 2006.

MAQUIAVEL, Nicolau. O Príncipe. Coleção Os Pensadores. Trad. Lívio Xavier. São Paulo: Abril Cultural, 1983.

PINTO, Céli Regina Jardim. Uma história do feminismo no Brasil. São Paulo: Fundação Perseu Abramo, 2003.

PLATÃO. A República. Trad. Maria Helena da Rocha Pereira. Lisboa: Calouste Gulbenkian, 1983.

RAWLS, John. O liberalismo político. Trad. Dinah de Abreu Azevedo. São Paulo: Ática, 2000.

RORTY, Richard. Philosophy and the mirror of nature. Nova Jersey: Princeton University Press, 1979.

SCHWARCS, Lilia; STARLING, Heloisa. Brasil: uma biografia. São Paulo: Companhia das Letras, 2015.

Trabalho enviado em 10 de julho de 2017.

Aceito em 21 de outubro de 2017. 